Methods: This study included patients with RA according to the ACR/EULAR 2010 classification criteria (American College of Rheumatology/European League Against Rheumatism) followed up in the Rheumatology Department of Rouen University Hospital and who had a haemoglobin $>12.5 \mathrm{~g} / \mathrm{dl}$. Patients were either from the single-centre monocentric longitudinal cohort or from the seventh visit of the VErA (Very Early Arthritis) High-Norman regional cohort. For each patient of the longitudinal cohort, DAS 28 ESR (Disease Activity Score - erythrocyte sedimentation rate) the FACIT - version 4 fatigue score (Functional Assessment of Chronic Illness Therapy) and a depression score (Hospital Anxiety and Depression Scale) were collected. Serum ferritin, transferrin, serum iron and saturation coefficient of transferrin were measured for each patient. ID was defined as serum ferritin $<50 \mu \mathrm{g} / \mathrm{L}$.

Results: One hundred and forty-one patients were included in the longitudinal cohort $(78.7 \%$ women, mean age $13.50 \pm 9.51$ years, positive rheumatoid factor and anti-citrullinated peptide antibodies in $83.6 \%$ and $86.5 \%$ of patients) and 74 RA patients from the VERA cohort $(70.3 \%$ women, mean disease duration 2.74 \pm 0.24 years). The prevalence of ID was $15.6 \%$ in the longitudinal cohort $(n=22 /$ $141)$ and $14.9 \%$ in the VErA cohort $(n=11 / 74)$. In the longitudinal cohort, there were no significant differences between ID patients and non-deficient patients in fatigue (mean FACIT of $27.80 \pm 12.4$ vs. $32.3 \pm 12.0 ; p=0.14$ ), disease activity (mean DAS 28 VS $2.85 \pm 1.38$ vs. $2.96 \pm 1.48 ; p=0.74$ ) and depression (mean HAD score $5.86 \pm 4.12$ vs. $5.80 \pm 3.84$; p not calculated).

Conclusions: The prevalence of ID without anaemia was similar between early and old RA and was similar to that of the general French adult population $(15.5 \%) .{ }^{1}$ ID does not appear to be a major cause of fatigue in RA and does not affect the activity of the disease. The search for an ID is of limited value in exploring fatigue of RA patients.

REFERENCE:

[1] Institut National de Veille Sanitaire. Etude Nationale Nutrition santé, ENNS 2006.

Disclosure of Interest: None declared

DOI: 10.1136/annrheumdis-2018-eular.2972

\section{AB0346 INVESTIGATION OF ALEXITHYMIA IN PATIENTS AFFECTED BY RHEUMATOID AND PSORIATIC ARTHRITIS: CROSS-SECTIONAL OBSERVATION}

G.L. Fonti, M.S. Chimenti, P. Conigliaro, J. Hitaj, M. Galluzzo, M. Talamonti, B. Kroegler, E. Greco, R. Perricone. Policlinico Tor Vergata, Rome, Italy

Background: Rheumatoid arthritis (RA) and Psoriatic arthritis (PsA) are chronic inflammatory diseases that lead to an overthrow of articular structure, functional limitation and disability. Alexithymia is a personality trait characterised by deficits in cognitive processing and regulation of emotions. A broad association between alexithymia and symptoms as depression, inflammation and pain has been demonstrated.

Objectives: to evaluate the prevalence of alexithymia in patients affected by Rheumatoid and Psoriatic arthritis.

Methods: We prospectively enrolled, from January to December 2017, patients affected by RA diagnosed according to the ACR revised criteria and PSA diagnosed according to the CASPAR criteria referred to the out-patients clinic of the Rheumatology Unit of Policlinico Tor Vergata, Rome. The 20-item Toronto Alexithymia Scale (TAS-20) was used to assess alexithymia. Disease activity, function and quality of life, clinimetric tests as well as ESR and CRP were assessed.

Statistical comparisons were performed using Pearson's Coefficient of Skewness, the unpaired t-Test and Mann-Whitney test.

Results: A total of 50 RA patients and 51 PsA patients were enrolled (table 1). The TAS-20 score showed that $38.6 \%$ (39/101) of patients had alexithymia, $26.7 \%(27 / 101)$ patients were in the borderline of alexithymia and $34.7 \%(35 / 101)$ patients had not alexithymia. A statistical significant association was observed between alexithymia and inflammatory indeces (ESR: $p=0.029, C R P: p=0.043$, figure 1 and 2) and also between alexithymia and clinimetrics parameters (ptVAS, pVAS, $\mathrm{GH}, \mathrm{p}<0.0001$ for all comparisons). No correlations were observed between alexithymia and disease duration, gender, therapies with bDMARDs. A significant trend has been demonstrated between alexithymia and corticosteroidal therapy
Abstract AB0346 - Table 1. Characteristics, therapies and clinimetric evaluation of the study population

\begin{tabular}{cccc}
\hline & RA & APs & Total \\
\hline Female Sex - No. (\%) & $41(40.6 \%)$ & $31(30.7 \%)$ & $72(71.3 \%)$ \\
\hline Male Sex- No. (\%) & $20(19.8 \%)$ & $9(8.9 \%)$ & $29(28.7 \%)$ \\
\hline Ago (years) in mean \pm (DS) & $59.5 \pm(11.46)$ & $52.6 \pm(12.84)$ & $56 \pm(12.66)$ \\
\hline Mean Discase Duration \pm (DS) & $6.19 \pm(3.82)$ & $6.29 \pm(3.96)$ & $6.24 \pm(3.89)$ \\
\hline Patients on csDMARDs - No. (\%) & $10(9.9 \%)$ & $34(33.6 \%)$ & $44(43.5 \%)$ \\
\hline Paticnts on bDMARDs - No. (\%) & $12(11.8 \%)$ & $38(37.6 \%)$ & $50(49.5 \%)$ \\
\hline Paticnts on steroids - No. (\%) & $37(36.6 \%)$ & $12(11.9 \%)$ & $49(48.5 \%)$ \\
\hline paticnt VAS (0.100) & $42.6 \pm(20.95)$ & $58.23 \pm(26.52)$ & $50.49 \pm(25.17)$ \\
\hline pain VAS (0-100) & $38.1 \pm(20.87)$ & $56.9 \pm(26.59)$ & $47.59 \pm(25.71)$ \\
\hline GH (0.100) & $44 \pm(23.08)$ & $49.7 \pm(22.58)$ & $46.88 \pm(23.01)$ \\
\hline
\end{tabular}

Data are expressed as Mean \pm Standard Deviation; csDMARDs: conventional synthetic disease-modifying antirheumatic drugs; bDMARDs: biological disease-modifying antirheumatic drugs; VAS: Visual Analogic Scale; GH: Global Health; percentages calculated for total population.

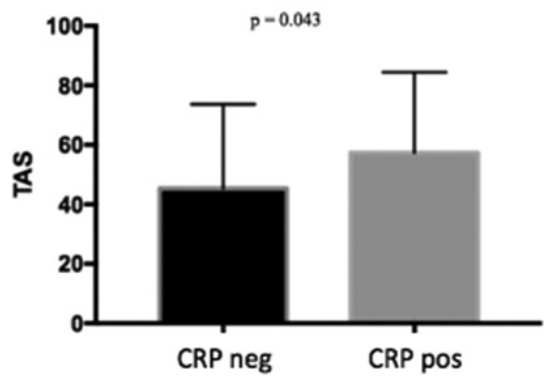

Abstract AB0346 - Figure 1

Conclusions: This study suggests that alexithymia assessment should be a part of the comprehensive care of patients with RA and PsA. We are in the process of extending this investigation on a larger sample population to improve our investigation field and to consolidate our dates.

Disclosure of Interest: None declared

DOI: 10.1136/annrheumdis-2018-eular.4919

\section{AB0347 BODY COMPOSITION IN PATIENTS WITH RHEUMATOID ARTHRITIS KAZAKH NATIONALITY}

G. Gabdulina, A. Tokarev, D. Mussabaeva. Kazakh Medical University, Almaty, Kazakhstan

Background: Chronic inflammation in rheumatoid arthritis (RA) leads to a decrease in fat and muscle mass [Baker J.F., Von Feldt J. Mostoufi-Moab S. et al. 2014 Low muscle mass in RA is considered as the main criterion of sarcopenia. Recently, much attention has been paid to various phenotypes of sarcopenia, among which osteopenic sarcopenia, sarcopenic obesity and osteosarcopic obesity (most unfavourable in terms of functional disorders) are distinguished. In the modern literature there are works devoted to changes in the composition of the body in the aspect of abdominal obesity and its influence on cardiovascula risk in RA [Crowson C.S., Myasoedova E., Davis J.M., 2011). Studies with the evaluation of muscle mass and sarcopenia in RA are few. In Kazakhstan, the composition of the human body was not studied.

Objectives: The purpose of the study was to study the body composition (muscle and fat mass) of patients with RA of Kazakh nationality using bioelectrical impedance analysis.

Methods: In our study we used Bioimpedance analyzer 101 (BIA 101, Italy).

Bioimpedansometry was performed in 585 participants, including 295 patients with RA and 290 of their siblings.

Results: In patients with RA, in contrast to the comparison group (sibs), BMI (probands $-25.34 \pm 5.1$, siblings $-24.86 \pm 4.45$ ), the girth of the waist and hips were slightly higher than those of the siblings. The ratio of RT/OB in both groups was virtually the same. At the same time, a decrease in the lean mass was found 
(probands $-45.37 \pm 12.2$, siblings $-48.67 \pm 11.01$ ), which, in all probability, is due to sarcopenia. The presence of sarcopenia is also confirmed by a decrease in the sarcopenia index (probands $0.6884 \pm 0.1$, sibs $0.6947 \pm 0.1$ ). On the contrary, the fat content of RA patients is higher than that of siblings.

Conclusions: Thus, in our patients cachexia is formed in RA, which is characterised by loss of muscle mass with the preservation or even growth of fat mass, which stabilises body mass indexes, and in some cases even leads to its increase (so-called cachexial obesity).

\section{REFERENCES:}

[1] Baker JF, Von Feldt J, Mostoufi-Moab S, et al. Deficits in muscle mass, muscle density, and modified associations with fat in rheumatoid arthritis. Arthritis Care Res (Hoboken) 2014;66(11):1612-18.

[2] Crowson CS, Myasoedova E, Davis JM 3rd, et al. Increased prevalence of metabolic syndrome associated with rheumatoid arthritis in patients without clinical cardiovascular disease. J Rheumatol 2011;38(1):29-35.

Disclosure of Interest: None declared

DOI: 10.1136/annrheumdis-2018-eular.1425

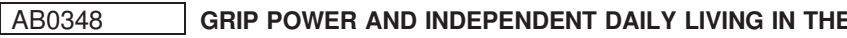 PATIENTS WITH RHEUMATOID ARTHRITIS}

H. Ishikawa ${ }^{1}$, A. Abe ${ }^{1}$, T. Kojima ${ }^{2}$, M. Kojima ${ }^{3}$, N. Ishiguro ${ }^{2}$, S. Ito ${ }^{1}$, A. Murasawa ${ }^{1}$. ${ }^{1}$ Rheumatology, Niigata Rheumaric Center, Shibata city, Niigata; ${ }^{2}$ Orthopedic Surgery, Nagoya University Hospital; ${ }^{3}$ Medical Education, Nagoya City University Hospital, Graduate School of Medicine, Nagoya city, Japan

Background: Grip power is known to be a simple and useful objective index that can be used in the self-assessment of disease activity in patients with rheumatoid arthritis $(R A)^{1}$. However, the clinical significance of this physical function is unknown.

Objectives: The objective of this study was to clarify the relationship between the grip power and the level of activities of daily living (ADL).

Methods: The grip power was measured in 221 inpatients of our hospital with RA using a mercury dynamometer. The independence level ( 0 : impossible, 1 : incomplete and not practical, 2: practical but the means thereof are unusual, 3: normal) for $44 \mathrm{ADL}$ items, including most daily activities was investigated. For each item, the site with the problem (shoulder, elbow, forearm, wrist, thumb, fingers, lower extremity and trunk) and cause of disability (pain, loss of power, decreased range of motion, abnormal prehensile pattern and fatigue) were investigated by interviewing the patient. There were 33 male and 188 female patients. The average age of the patients was 64.6 years, and the average duration of the disease was 13.3 years. Biological therapy had been given to $23 \%$ of the patients. The average grip power of the right and left hands was used.

Results: There were 14 items requiring others' assistance (level 0 or 1 ) in more than $10 \%$ of patients. For these 14 items of ADL, the grip power increased with the increase in the independence level $(p<0.001)^{2}$. The site with a problem was, in order of frequency, the fingers $(26.1 \%)$, wrist $(14.8 \%)$ and lower extremity $(14.0 \%)$. The cause of disability was, in order of frequency, pain (38.8\%), loss of power (32.8\%) and a decreased range of motion. Based on the results of a stepwise regression analysis, the first factor, consisting mainly of "reaching function", including "hair dressing", "washing one's body", "taking on and off one's shoes", "clipping nails", "buttoning", etc., was most strongly related to a loss of grip power and problems at the elbow, the shoulder and the wrist. The second factor, consisting mainly of the "prehensile function", including "opening a plastic bottle", "opening lids", "squeezing towels", etc., was most strongly related to a loss of grip power and problems at the wrist and the thumb. The third factor, consisting mainly of "activities involving changing body position and transfer", including "getting in and out of the bathtub", "standing and sitting", etc., was most strongly related to ageing and problems with the lower extremities and at the elbow and the wrist. In the receiver operating characteristic $(\mathrm{ROC})$ curve, the grip power with the maximum Youden index was $136.5 \mathrm{mmHg}(11.8 \mathrm{~kg})$ in females and $152.5 \mathrm{mmHg}(13.5 \mathrm{~kg})$ in males. Most activities were performed independently with the grip power more than $136.5 \mathrm{mmHg}$ in females (figure 1). The explanatory variables for the grip power in the female patients were ageing; a long disease duration; a high disease activity score (DAS) 28; problems at the fingers, the thumb and the elbow; decreased flexion at the shoulder and a decreased range of forearm rotation.

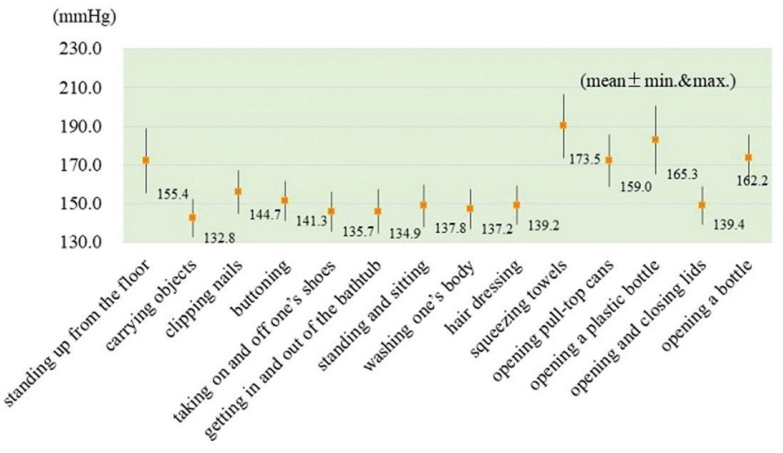

Abstract AB0348 - Figure 1. Minimally required grip power to perform daily activities independently in females with level 3 after age adjustment

Conclusions: The grip power was a determinant of independent daily living in patients with RA in our study.

REFERENCES:

[1] Espinoza F, et al. Rheumatology (Oxford) 2016;55:897-901.

[2] Thyberg I, et al. Arthritis Rheum 2005;53:886-96.

Disclosure of Interest: None declared

DOI: 10.1136/annrheumdis-2018-eular.1861

\section{AB0349 OTO-RHINO-LARYNGOLOGICAL MANIFESTATIONS OF RHEUMATOID ARTHRITIS}

S. Zrour ${ }^{1}$, H. Mouanaa ${ }^{1,2}$, N. kolsi $^{3}$, H. Hachfi ${ }^{2}$, A. Arfa ${ }^{1}$, M. Jguirim ${ }^{1}$, I. Bejia ${ }^{1}$, T. Mongi ${ }^{1}$, M. Youness ${ }^{2}$, J. Koubaa ${ }^{3}$, N. Bergaoui ${ }^{1} .{ }^{1}$ Rheumatology Departement of Monastir University Hospital, Monastir, ${ }^{2}$ Rheumatology Departement of Mahdia University Hospital, Mahdia; ${ }^{3}$ ENT Departement of Monastir University Hospital, Monastir, Tunisia

Background: Rheumatoid arthritis (RA) is a chronic inflammatory disorder that can damage a wide variety of body systems. Ear, nose and throat (ENT) involvement is frequent but not often reported. The purposes of our work are to determine the prevalence of ENT involvement during RA and to evaluate its correlation with RA disease activity.

Objectives: The purposes of our work are to determine the prevalence of ENT involvement during RA and to evaluate its correlation with RA disease activity.

Methods: This is a cross-sectional study of 90 consecutive RA, followed at the Rheumatology department of Monastir Teaching Hospital in Tunisia, during 06 months (November 2016 to April 2017) and 46 matched volunteers. ENT clinical examination with tonal audiometry and thyroid tests (TSH, T4, anti-Thyroperoxidase $\mathrm{Ab}$ (Anti TPO Ab) and Anti-Thyroglobulin $\mathrm{Ab}$ ( $\mathrm{Ab}$ anti Tg) were performed.

Results: ENT involvement prevalence was $78 \%$. The most frequent functional signs were intermittent dysphonia in $50 \%$ and dysphagia in $42 \%$ of cases. The neck examination revealed painful larynx mobilisation in $58 \%$ cases and cervical lymph nodes in $7 \%$ of cases. Indirect laryngoscopy, performed in the $67 \%$ of symptomatic patients, noted inflammatory mucosa in $38 \%$ of cases and decrease in vocal cord mobility in $8 \%$ of cases. Seventy percent patients had temporomandibular Joint (TMJ) involvement. Tonal audiometry revealed $42 \%$ of cases of deafness: $27 \%$ sensorineural deafness, $13 \%$ conductive deafness and $2 \%$ cases mixed hearing loss. The ENT manifestations significantly associated to RA compared to the witness group $(p<0.01)$ were intermittent dysphonia, dysphagia, painful larynx mobilisation, inflammatory nasal mucosa, painful TMJ and deafness. Active disease (DAS $28>3.2)$ is statistically associated with deafness ( $p \leq 0.048)$ and TMJ involvement $(p \leq 0.009)$. Logistic regression study shows that RA duration over 10 years was associated to laryngeal dyspnea (OR=4.4, $\mathrm{p} \leq 0.012$, IC $(95 \%)$ $[1.377,14.134])$ and deafness (OR=3.8, $p \leq 0.03, \operatorname{IC}(95 \%)[1.142,12.882])$. In the other hand, RA moderate functional handicap is a protective factor $(\mathrm{OR}=0.123$, $\mathrm{p} \leq 0.016$, IC $(95 \%)[0.076,0.772])$ of ENT involvement and biotherapy use was associated to thyroid involvement (OR=7.8, $\mathrm{p} \leq 0.017, \mathrm{IC}(95 \%)[1.431,43.175])$. Conclusions: ENT involvement is a very common, usually asymptomatic extraarticular manifestation during RA. It is, mainly, TMJ involvement, deafness and dysphonia. The main relevant determinants are RA disease activity and duration.

\section{REFERENCES:}

[1] Minichiello, Émeline, Luca Semerano, et Marie-Christophe Boissier. Évolu tion dans le temps de la polyarthrite rhumatoïde: incidence, prévalence, gravité. Revue systématique de la littérature. Revue du Rhumatisme 2017 janvier 1;84(1):9-16. 